\title{
Improving Patient Care Through Workspace Renovation and Redesign: A Lean Approach
}

Tommy Koonce, MD, MPH; Dana Neutze, MD, PhD

\begin{abstract}
BACKGROUND AND OBJECTIVES: At a time when the US health care system needs greater access to comprehensive, on-demand primary care, the University of North Carolina Family Medicine Center found itself struggling to meet patient demands within the confines of an outdated facility. Clinic leadership sought to redesign the physical space to expand capacity, integrate other members of the care team, support extended hours of operation, and improve patient experience.
\end{abstract}

METHODS: Clinic leadership employed experienced lean coaches to train our entire department in lean methodology, to implement a comprehensive approach to redesigning our workflows, and to use those perfected workflows to redesign and renovate our new clinical workspace.

RESULTS: Upon completion of the renovation and redesign, the clinic experienced significant growth in patient volumes $(24 \%)$ and unprecedented improvement in patient satisfaction (89th to 92 nd percentile).

CONCLUSIONS: Lean methodology proved to be an effective strategy for analyzing our current workflows and use of physical space. Moreover, lean strategies proved vital for redesigning and renovating our clinic.

(Fam Med. 2020;52(6):435-9.)

doi: 10.22454/FamMed.2020.429243

$\mathbf{T}$ he ambitious challenge of a patient-centered medical home, ${ }^{1,2}$ and even more so value-based payment models, require clinics that efficiently deliver broad ranging services on an as-needed basis. ${ }^{3}$ As family medicine evolves to meet increased demands, the impact of physical workspace is often overlooked. Unfortunately, traditional office design impedes the effectiveness of primary care teams in multiple ways. ${ }^{4}$

Built in 1990, the University of North Carolina (UNC) Family Medicine Center was once a state-of-theart facility. By 2011, faculty and staff

\section{Methods}

Clinic leadership partnered with the Office of Operational Efficiency $(\mathrm{OE})$ to use lean methodology in renovation and redesign efforts. ${ }^{5}$ Lean methodology originates from Toyota manufacturing. It emphasizes value to the customer through continuous improvement and respect for all members of the team. Thus, all members of the clinical operation are trained and encouraged to continually identify areas of waste and eliminate steps that do not add value to the patient. Long before any construction work, lean coaches trained clinic leadership, faculty, staff, and members of the patient advisory council to ensure buy-in and a working understanding of lean principles at all organizational levels (Table 1). Once the clinic had embraced lean thinking, clinic leadership assembled a multidisciplinary team of providers, staff, patients, architects, and quality improvement coaches to renovate and redesign our clinical space and workflows using multiple lean methodologies (Table 2).

The team observed our current state and several key findings emerged. Patients spent too much time waiting at various steps in their visit (eg, in line to check in). Providers spent too much time outside of the exam room (eg, looking the clinical capacity and enhance patients' overall experience. 
for supplies). Patients had to walk through the building too much to access services (eg, lab). Patients had little sense of privacy during the check-in and check-out processes.

The team then envisioned and mapped the care we aspired to provide. Using lean principles, we examined the gaps between our current and future state. We then identified metrics that would measure progress toward our ideal state. To evaluate changes in patient care capacity, we identified total number of patient visits, total patient cycle time, and the amount and proportion of space dedicated to actual patient care as our main outcomes of interest. To evaluate patient experience, we chose Press Ganey patient satisfaction surveys as our key indicator of success.

Through the lean redesign process, new patient flow was mapped out and endorsed by faculty, staff, and patients, and subsequently the team worked with architects to design a physical space to support their vision. The team completely

Table 1: Lean Transformation Prerequisites

\begin{tabular}{|l|}
\hline Engaged leadership \\
\hline Training and involvement at all staff levels \\
\hline Protected staff and provider time to participate in improvement events \\
\hline Experienced lean coaches \\
\hline Data management capacity \\
\hline Engaged patient advisory council \\
\hline
\end{tabular}

redesigned the patient experience, eliminating waste and streamlining patient movement through the visit (Table 3). This included bold changes like eliminating the check-in desk in exchange for a process wherein every patient was briefly greeted at the front door and then taken to their exam room for check-in. To minimize loss of patient care capacity during renovation, we converted a former waiting area into examining rooms first, and then remodeled one module of four at a time.

The UNC Institutional Review Board approved this study as exempt from formal review (\#19-1651).

\section{Results}

At the conclusion of this roughly $\$ 3$ million project, the UNC Family Medicine Center accomplished several outcomes. First, the amount of space dedicated to clinical care increased by $31 \%$, from 14 to 18.4 exam rooms per 10,000 square feet with a net increase from 35 to 46 rooms dedicated to clinical care, plus rooms dedicated to nutrition,
Table 2: Lean Strategies and Terminology

\begin{tabular}{|l|l|}
\hline \multicolumn{1}{|c|}{ Term or Strategy } & \multicolumn{1}{c|}{ Description } \\
\hline A3 thinking & $\begin{array}{l}\text { A structured problem-solving method organized in nine steps: } \\
\text { (1) reason for action, (2) current state, (3) target state, (4) gap analysis, (5) solution approach, (6) } \\
\text { rapid experiments, (7) completion plan, (8) confirmed state, (9) insights } \\
\text { A format and physical form for mapping progress through a lean transformation }\end{array}$ \\
\hline Value stream analysis & $\begin{array}{l}\text { A structured process of observing and diagraming the current state of workflow with the intent } \\
\text { of identifying actions and activities that add value for the customer and eliminating those that } \\
\text { do not }\end{array}$ \\
\hline Gemba walk & Direct observation of the actual place where work occurs \\
\hline Kaizen event & $\begin{array}{l}\text { A 4- to 5-day rapid improvement event involving a cross-sectional team of providers and staff } \\
\text { focused on improving one aspect of workflow within the value stream }\end{array}$ \\
\hline 2P event & $\begin{array}{l}\text { Preparation/process-an exercise of running operational simulations through a proposed space, } \\
\text { ideally at actual scale under realistic conditions }\end{array}$ \\
\hline
\end{tabular}

physical therapy, behavioral health, and group visits (Figure 1). Increased clinical space and streamlined workflow allowed an increase from a prerenovation maximum of roughly 384 to a postrenovation capacity for over 480 patients per day.

We achieved this increase in space and efficiency without sacrificing patient visits during renovation. Careful staging of the renovation allowed us to increase patient visits by $10 \%$ during the construction time frame.

Once the renovation was complete, total patient cycle time improved from an average of 74 minutes per visit to a low of 53 minutes (Figure 2). Additionally, repurposed nonclinical space allowed for the eventual implementation of a dedicated urgent care space, drastically improving on-demand access to our patients and the community and further increasing capacity.

Overall patient satisfaction improved from 89.2 in 2014 to 93.7 in 2017 (Figure 3) and our patients' sense of privacy improved from the 30th percentile among large health care systems to the 81 st percentile (Figure 4).

\section{Discussion}

Our experience indicates lean methodology is an effective tool for redesigning patient flow and planning clinical space. The processes we implemented allowed us to envision and create new clinical space that was more efficient, private, and 
satisfying for our patients. We were also able to successfully integrate additional members of the health care team into our workflow.

As more clinics embrace the principles of a patient-centered medical home or transition to value-based models, lean processes could be used to redesign existing clinical space and design more comprehensive indirect care.

We benefitted from a highly motivated, talented leadership team with significant experience and buy-in regarding lean methodology. They were able to quickly pick up new lean principles and communicate earnestly about their value with colleagues. In addition, UNC HealthCare has a large team of expert lean coaches. Our project was supported by a health care system that highly values the contribution of primary care, and to them, the return on investment was clear. These factors may have contributed to a more successful than usual lean transformation of our workflow and space.

In conclusion, the application of lean principles led to a successful transformation of our clinic. Patient satisfaction and sense of privacy increased. Total cycle time decreased. Multiple clinical quality metrics increased. The number of patients seen

Table 3: Lean Transformation Changes Implemented During Redesign

\begin{tabular}{|l|}
\hline Eliminate waiting rooms \\
\hline Standardize exam rooms \\
\hline Simplify and clarify way-finding \\
\hline Eliminate nursing station \\
\hline $\begin{array}{l}\text { Colocate providers and medical assistants at work stations between exam } \\
\text { rooms }\end{array}$ \\
\hline Convert underutilized office space to clinical space \\
\hline Centralize supply storage \\
\hline Colocate phone room and nurse triage teams \\
\hline Centralize resident precepting space \\
\hline
\end{tabular}

Figure 1: Family Medicine Center Layout

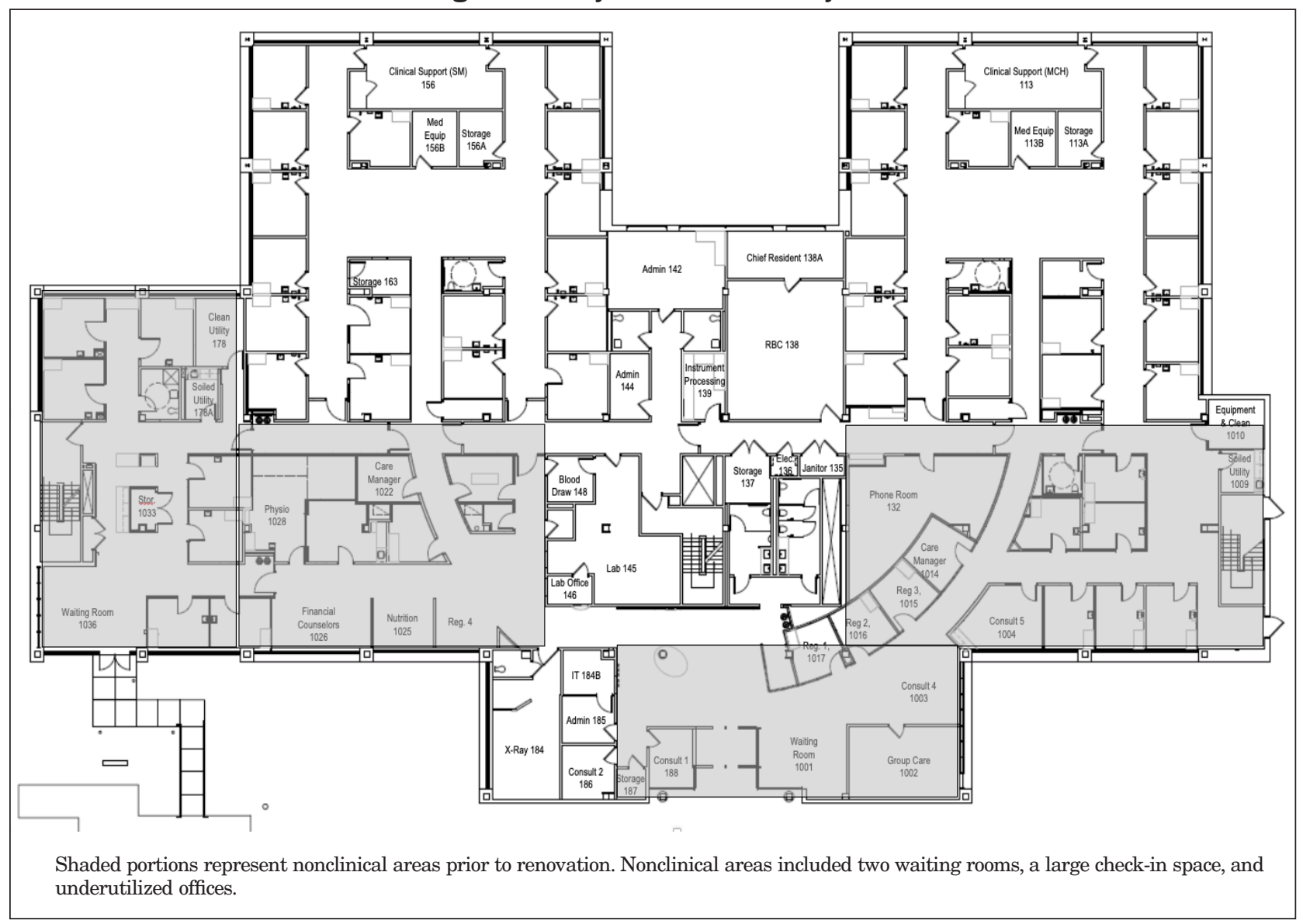


Figure 2: Median Patient Cycle Time (From Door-In to Door-Out), by Month

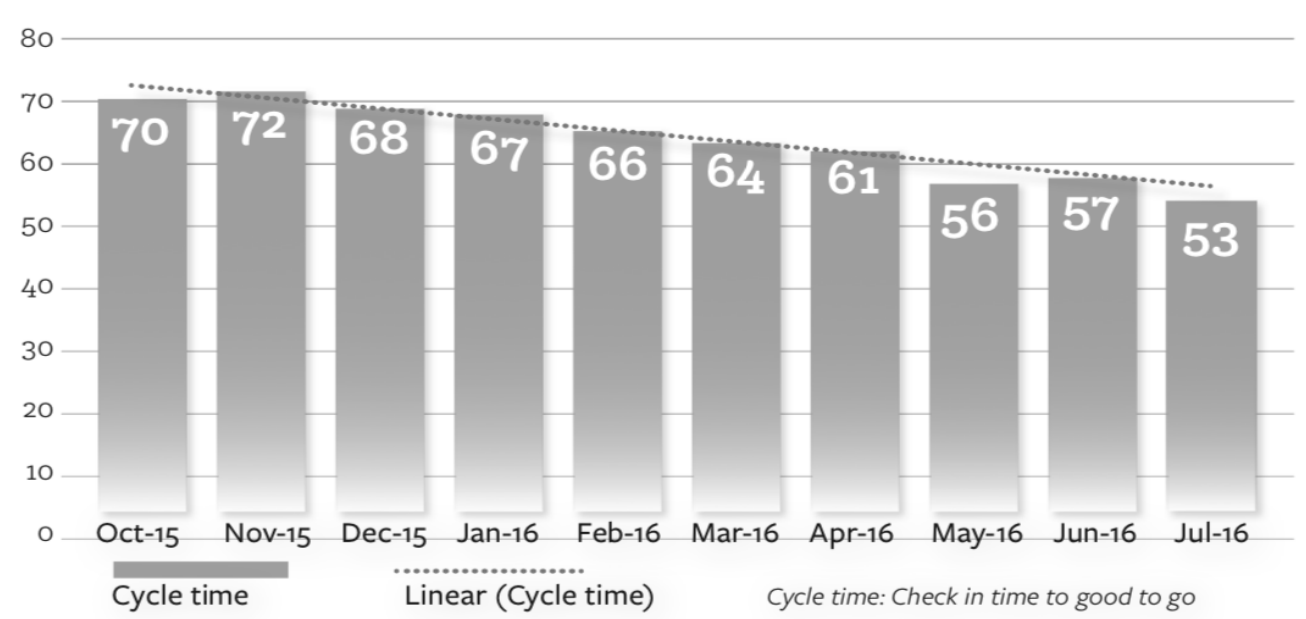

Source: direct observation of at least 30 patient encounters per month

Figure 3: Overall Patient Satisfaction according to Press Ganey Email Patient Surveys From January 2015 to June 2016

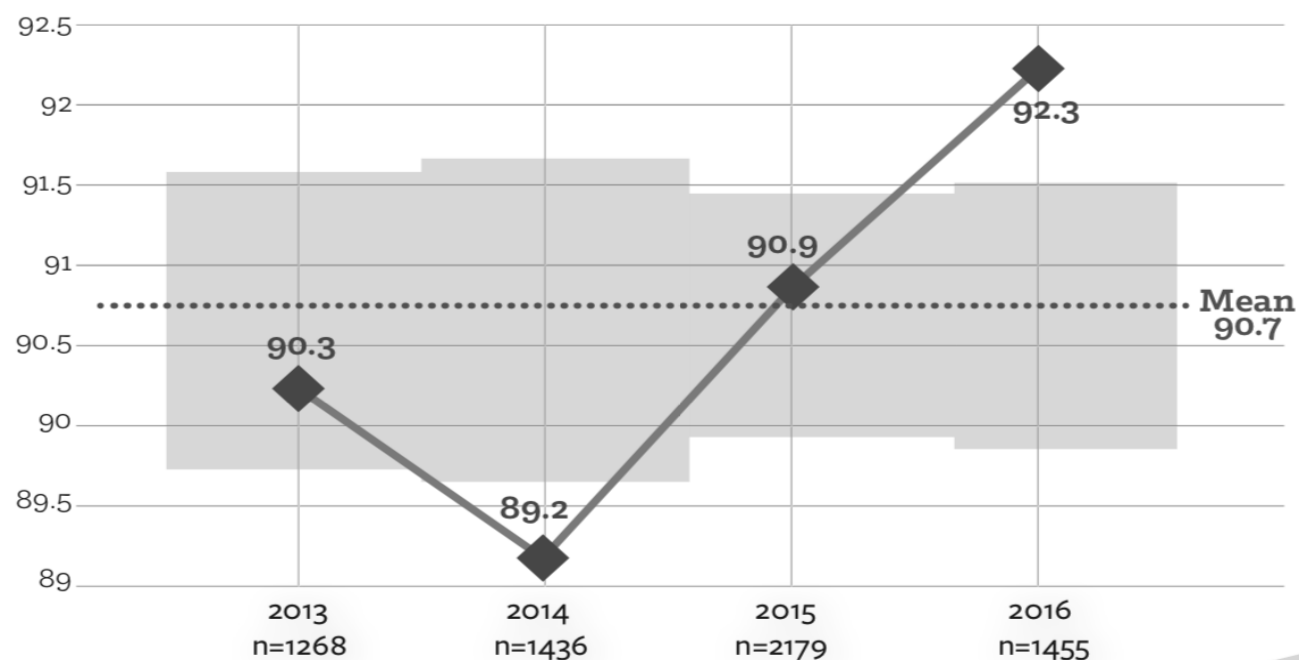

Shaded area represents the $95 \%$ confidence interval for all practices, with half the width approximating the degree of change that would be statistically significant. 
Figure 4: Patient Satisfaction: Patient Privacy

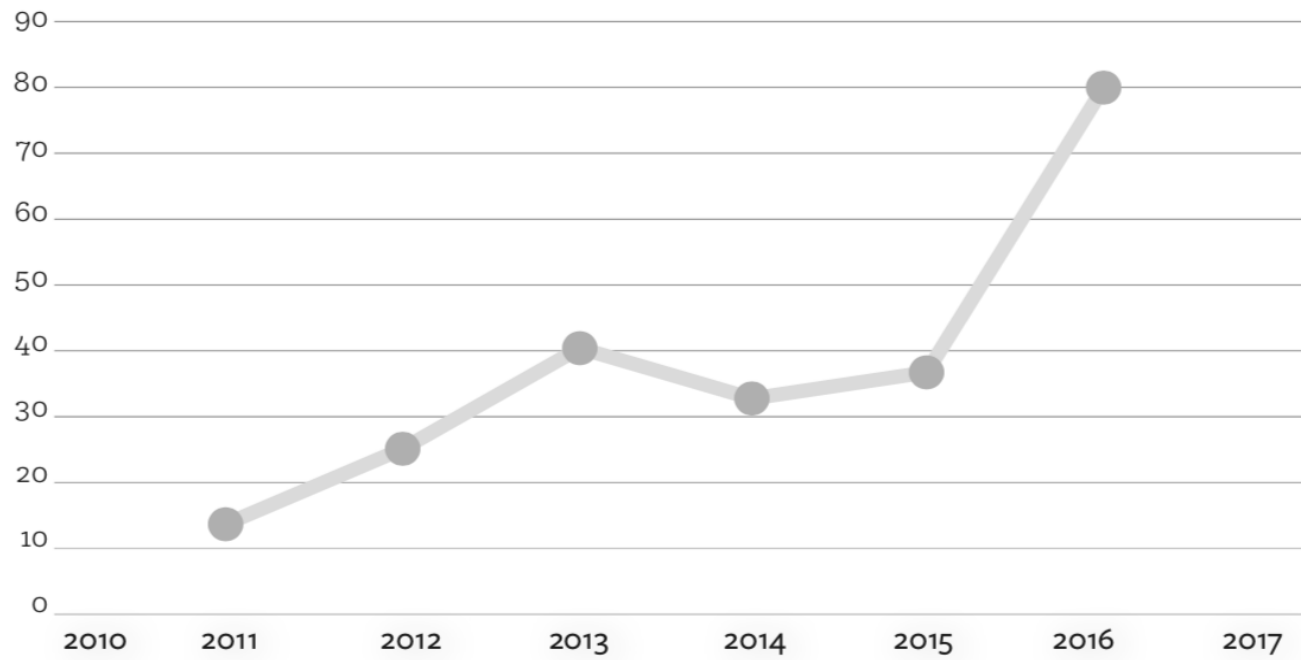

Taken from Press Ganey question specifically addressing patient privacy.

Renovation from January 2015 to June 2016.

$\mathrm{Y}$ axis=percentile among large health care systems.

CORRESPONDING AUTHOR: Address correspondence to Dr Tommy Koonce, 590 Manning Dr, Chapel Hill, NC 27599. 984-974-0210. Fax: 919-966-6126. thomas_koonce@med.unc.edu.

\section{References}

1. Epstein, AJ. The role of public clinics in preventable hospitalizations among vulnerable populations. Health Serv Res. 2001; 36:405420
2. Yarnall KS, Østbye T, Krause KM, Pollak KI, Gradison M, Michener JL. Family physicians as team leaders: time to share the care. Prevention of Chronic Disease. 2009; 6(2): A59.

3. Enthoven, AC, Crosson, FJ, Shortell SM. Redefining health care: medical homes or archipelagos to navigate? Health Aff (Millwood). 2007; 26:1366-1372.
4. McGough P, Jaffy M, Norris T, Sheffield P, Shumway M. Redesigning your workspace to support team-based care. Fam Pract Manag. $2013 ; 20(2): 20-24$

5. Lawal AK, Rotter T, Kinsman L, et al. Lean management in health care: definition, concepts, methodology and effects reported (systematic review protocol). Syst Rev. 2014;3(1):103. 